Available online at GSC Online Press Directory

GSC Biological and Pharmaceutical Sciences

e-ISSN: 2581-3250, CODEN (USA): GBPSC2

Journal homepage: https://www.gsconlinepress.com/journals/gscbps

(RESEARCH ARTICLE)

\title{
Effects of gamma irradiation on submergence tolerance of two selected varieties of lowland rice (Oryza sativa L.)
}

\author{
Mohammed Jiya ${ }^{1, *}$, Falusi Olamide ${ }^{1}$, Daudu Oladipupo Abdulazeez Yusuf ${ }^{1}$, Abubakar Abdulhakeem 1, \\ Muhammad Liman Muhammad ${ }^{1}$, Salihu Bolaji Zulukanaini ${ }^{2}$ and Titus Segun David ${ }^{1}$ \\ ${ }^{1}$ Department of Plant Biology, Federal University of Technology Minna, Niger State, Nigeria \\ ${ }^{2}$ National Cereal Research Institute Badeggi, Niger State, Nigeria
}

Publication history: Received on 20 February 2018; accepted on 08 March 2018

https://doi.org/10.30574/gscbps.2018.2.3.0017

\begin{abstract}
The study was carried out to assess the effect of different doses of gamma irradiation on agro-morphological traits under simulated flooding of two rice varieties (FARO 44 and FARO 60) in order to identify the most effective radiation dose in creation of genetic variability for submergence tolerance. Seeds of FARO 44 and FARO 60 cultivars were collected from National Cereal Research Institute (NCRI) Badeggi, Nigeria and exposed to different doses of gamma irradiation (0, 50,100, 150 and 200 Gy) at Center for Energy and Research Training, Zaria, Nigeria. The treated and the controls seeds were evaluated for submergence in a Randomized Complete Block Design with four replicate each. Each experimental bucket was flooded for a period of 10 days and was allowed to grow till harvest after submergence period. From the results, gamma irradiation had significant $(\mathrm{P} \leq 0.05)$ positive effect on survival percentage of FAR0 44 after submergence with 150 Gy having the highest (93.75\%) compared to the control (56.25\%). The irradiation doses (150 and 200 Gy) had significant positive effects $(\mathrm{p} \leq 0.05)$ on the plant height and yield of FARO 44. In Faro 60, low doses of gamma irradiation $(100 \mathrm{~Gy})$ had significant ( $\mathrm{p} \leq 0.05)$ effects on the days to $50 \%$ flowering and weight of 100 grains (g). It was observed that gamma radiation doses of $150 \mathrm{~Gy}$ and $200 \mathrm{~Gy}$ had positive effects on submergence tolerance indices of FARO 44 used in this research. Further research therefore should be carried out on submergence tolerance of the promising mutants.
\end{abstract}

Keywords: FARO 44; FARO 60; Gamma irradiation; Submergence tolerance

\section{Introduction}

Rice is one of the most important food crop in the world, consumed by nearly 3 billion people daily. Rainfed lowland and deep water rice cultivars are cultivated on approximately $33 \%$ of global rice farmlands [1]. This accounts for about 50 million hectares of the estimated 150 million hectares of rice fields under cultivation worldwide [2]. More than 16 million hectare of rice lands of the world in lowland and deep-water rice areas are unfavorably affected by flooding. Submergence caused by flash flood is a key factor limiting the yield of lowland rice. In Nigeria, approximately $70 \%$ rainfed lowland rice farms are prone to seasonal flooding, this results in total loss of the crop. These losses affect rice farmers in rained and flood-affected areas where alternative livelihoods are limited. Therefore, the incidences and severity of poverty in these areas are high [1]. During any given year, yield losses in Nigeria resulting from flooding may range from 10 percent to total destruction [3].

Submergence tolerance is defined as the ability of a rice plant to survive and continue growing after being completely submerged in water for several days [1]. Recently, the extent of submergence stress has increased due to extreme

\footnotetext{
${ }^{*}$ Corresponding author

E-mail address: mijiya0811308016@ gmail.com
}

Copyright (@) 2018 Author(s) retain the copyright of this article. This article is published under the terms of the Creative Commons Attribution Liscense 4.0. 
weather events such as unpredicted heavy rains that have flooded wider areas across many states of the country. Among the most frequently and severely affected states in Nigeria are Kebbi, Niger, Kogi and Taraba states which together account for over $80 \%$ of lowland rice ecology in Nigeria. The experts say the situation may become worst as climate change progresses.

Flash floods are highly unpredictable and can occur at any growth stage of the rice crop, resulting in yield loss of $10 \%$ to $100 \%$, depending on water depth, duration of submergence, temperature, turbidity of water, light intensity, and age of the crop [4]. Flooding is a serious constraint to rice plant growth and survival in rainfed lowland and deepwater areas. This is because it results in partial or complete submergence of the plant [3].

Gamma $(\gamma)$ rays are physical mutagens; gamma irradiation has proven to be a useful method for introducing new trait variations that may result in crop improvement and can be used as a complementary tool in plant breeding [5]. Induced rice mutants have been useful research tools for genetic and physiological assessments of yield-limiting factors in rice. Mutants have made it possible to identify critical elements for developing high yield potential varieties exhibiting desirable traits such as semi-dwarfism, early maturity, a greater number of panicles/plant and increased fertility. By 2003, 440 mutant rice varieties had been developed. Of these, 264 were produced by the direct application of mutagens and 176 were created by cross-breeding with induced mutants [6].

Submergence tolerance has long been regarded as an important breeding objective for rain-fed lowland and deep water rice areas [7]. Despite this recognition, there has been limited success in developing improved submergence tolerance in Africa particularly Nigeria. Keeping in view of this problem, the importance of improving submergence tolerance of some Nigerian cultivars cannot be over emphasized in the present rice improvement in Nigeria. The most relevant intervention to reduce vulnerability of lowland rice farms to submergence is to develop varieties that are submergence tolerance. Thus this research is design to evaluate for submergence tolerance of Faro 44 and Faro 60 under the effect of gamma irradiation.

\section{Materials and methods}

\subsection{Seed collection and treatment}

The genetic material (FARO 44 \& FARO 60) used for the study were collected from National Cereal Research Institute (NCRI) Badeggi, Nigeria and irradiated at Centre for Energy and Research Training Ahmadu Bello University Zaria, Nigeria. A total of five groups each of equal gram of seeds for FARO 44 and FARO 60 were irradiated with different doses $(0,50,100,150$ and $200 \mathrm{~Gy})$ of gamma ray using cesium - 137 source. The irradiated seeds were then raised in 10 liters experimental pots filled with sandy-loamy sand to 4 liters mark. Each treatment was replicated four times and arranged in Randomized Complete Block Design (RCBD) in the Botanical Garden of the Department of Plant Biology, Federal University of Technology Minna, Nigeria. The seedlings in the pots were subjected to complete submergence for a period of 10 days at 21 days seedling stage following the modified method of Akinwale et al. [1]. All agronomic practices were carried out when necessary and the plant monitored for agro-morphological parameters.

\subsection{Data analysis}

The Agro-morphological characteristic that were taken include plant number, plant height before and after the submergence, percentage survival after submergence, number of panicles at maturity, number of tillers at maturity, 100 seed weight, days to $50 \%$ flowering, days to maturity. Analysis of variance (ANOVA) was used to test for significance difference among the means and Duncan's multiple range test (DMRT) was used to separate the means where there were differences.

Survival $(\%)=\frac{\text { Number of survived plant after submergnece }}{\text { Number of plant before submergence }} \times 100$

\section{Results and discussion}

\subsection{Effects of gamma irradiation on germination percentage of FARO 44 and FARO 60}

The results effects of gamma irradiation on the percentage germination showed that increase in the dose of gamma irradiation decreases the germination percentage of both FARO 44 and FARO 60. The highest seed germination percentage was observed in the control plans for both FARO $44(100 \%)$ and FARO 60 (99\%), while the least was 
observed at 200 Gy of irradiation dose for FARO 44 (90\%) and FARO 60 (90\%) (Figure 1). The decrease in seed germination percentage with increasing doses may be attributed to disturbance at cellular as well as physiological levels. This result is in line with the work of Ahsan et al. [8] who observed decreasing effects on the germination percentage as the dose of gamma irradiation increases in two varieties of local rice, MRQ74 and MR269. Mushtaq and Rakesh [9] also reported that percentage germination were decreasing with an increasing doses of gamma irradiation of their work on wheat (Triticum aestivum $L$ ).

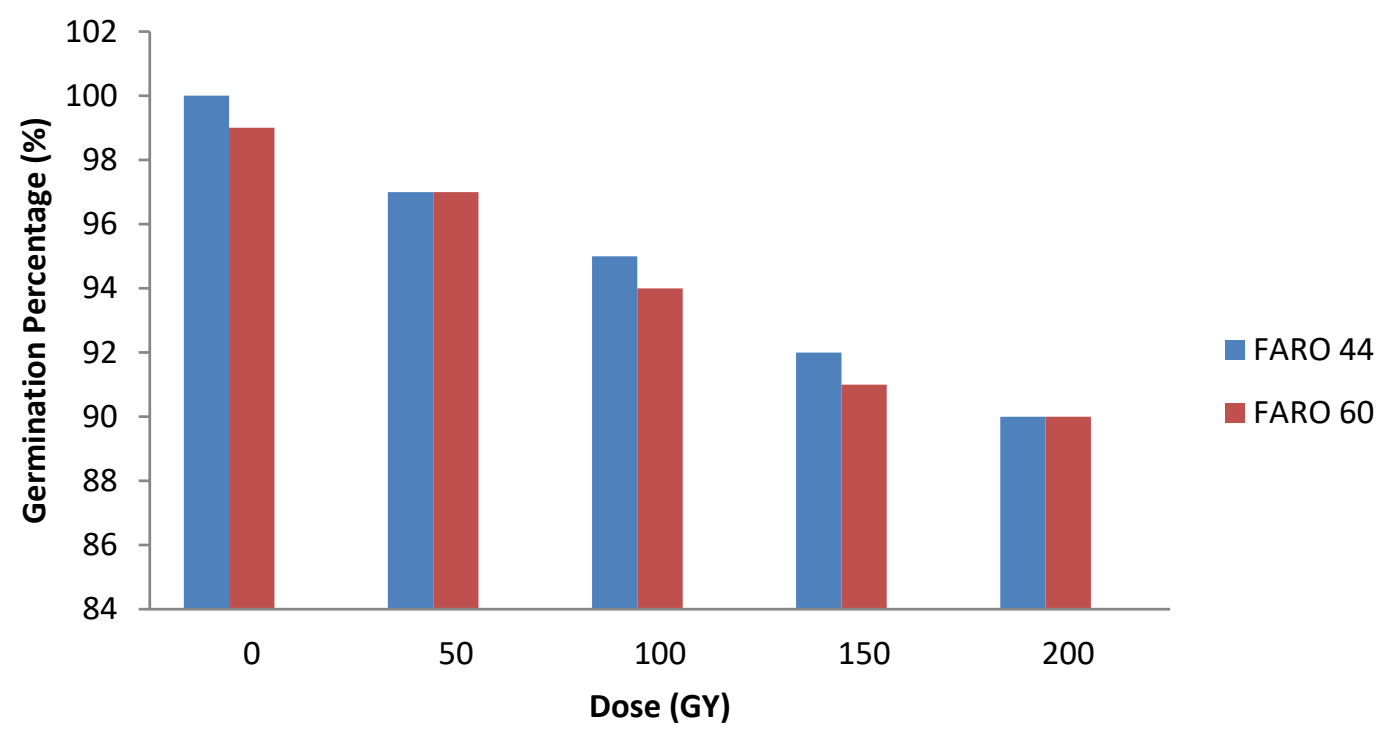

Figure 1 Effect of gamma irradiation on germination percentage of two Rice varaities

\subsection{Effects of gamma irradiation on the submergence tolerance indices of FARO 44 and FARO 60}

\subsubsection{Plant Height}

The result of the effects of gamma irradiation on the plant height before and after submergence and their survival are is shown in table 1. In FAR0 44, the plant heights recorded before submergence were not significantly (P $\geq 0.05$ ) influenced by the irradiation doses. However after submergence, a significant $(\mathrm{P} \leq 0.05)$ decrease in plant height was observed as the doses increases. In FARO 60, the control plants had the maximum plant height before submergence $(13.95 \mathrm{~cm})$ and after submergence $(17.75 \mathrm{~cm})$ respectively. On the other hand, plants exposed to 100 Gy had the lowest plant height $(8.63 \mathrm{~cm})$ before submergence, while plants exposed to $100 \mathrm{~Gy}$ and 150 Gy gamma irradiation had the lowest plant height $(10.75 \mathrm{~cm})$ after submergence.

Plants exposed to $150 \mathrm{~Gy}$ and 200 Gy gamma rays had significantly lowest plant height after submergence with the values if $19.50 \mathrm{~cm}$ and $19.43 \mathrm{~cm}$ when compare with the control $(30.63 \mathrm{~cm})$. This may be due to the fact that susceptible varieties tend to have rapid elongation during submergence which required carbohydrates and energy, leaving less available energy and maintenance required for survival during submergence while the tolerant varieties tend to limit stem elongation [1]. This result is in agreement with the work of Mushtaq and Rakesh [9], who observed a decrease in plant height as doses increase with the control recording the highest plant height.

\subsubsection{Survival Percentage (\%)}

Significant difference $(\mathrm{p}<0.05)$ were observed in respect to survival percentage of FARO 44 after 10 days submergence period. Plants exposed to 150 Gy had the highest survival percentage (93.75\%) while the control had the least survival percentage (56.25\%). These values were significantly different from all the values of other doses (Table 1). In FAR0 60, the control plants had the highest (62.50\%) survival percentage which was significantly different from the value of all other doses. On the other hand, plants exposed to $100 \mathrm{~Gy}$ of gamma irradiation had the lowest (37.50\%) survival percentage which was also significantly different from other doses (Table 1).

Survival percentage after submergence significantly increases as dose of gamma irradiation increases in FARO 44, however in FARO 60, the percentage survival decreases as gamma rays increases, except dose 150 Gy of gamma rays which surprisingly has the highest percentage survival over the control. According to Talebi et al. [10], the increasing 
frequency of chromosomal harm with increasing radiation dose may be responsible for reduction in plant survival. The reduction in plant survival due to the mutagenic treatments has also been reported in Pearl Millet [11] and Sesame [12]. Contrary to this, Animasaun et al. [13] reported that survival rate increased in untreated plant compare to the treated plants.

Table 1 Effects of gamma irradiation on submergence tolerance indices of FARO 44 and FARO 60

\begin{tabular}{|c|c|c|c|}
\hline $\begin{array}{l}\text { Varieties/Dose } \\
\text { (Gy) }\end{array}$ & $\begin{array}{l}\text { Height before } \\
\text { submergence }(\mathrm{cm})\end{array}$ & $\begin{array}{l}\text { Height after } \\
\text { de-submergence }(\mathrm{cm})\end{array}$ & $\begin{array}{l}\text { Survival } \\
\text { percentage (\%) }\end{array}$ \\
\hline \multicolumn{4}{|l|}{ FARO 44} \\
\hline 0 & $14.45 \pm 0.06^{\mathrm{a}}$ & $30.63 \pm 1.20^{\mathrm{b}}$ & $56.25 \pm 6.25^{\mathrm{a}}$ \\
\hline 50 & $11.45 \pm 2.00^{\mathrm{a}}$ & $24.63 \pm 2.75^{\mathrm{ab}}$ & $68.75 \pm 6.25^{\mathrm{ab}}$ \\
\hline 100 & $11.78 \pm 1.28^{\mathrm{a}}$ & $27.20 \pm 1.46^{b}$ & $62.50 \pm 21.65^{\mathrm{ab}}$ \\
\hline 150 & $14.95 \pm 0.10^{\mathrm{a}}$ & $19.50 \pm 3.13^{\mathrm{a}}$ & $93.75 \pm 6.25^{b}$ \\
\hline 200 & $14.95 \pm 0.13^{\mathrm{a}}$ & $19.43 \pm 2.12^{\mathrm{a}}$ & $87.50 \pm 7.22^{\mathrm{ab}}$ \\
\hline \multicolumn{4}{|l|}{ FARO 60} \\
\hline 0 & $13.95 \pm 2.52^{\mathrm{ab}}$ & $17.75 \pm 3.00^{\mathrm{a}}$ & $62.50 \pm 21.65^{b}$ \\
\hline 50 & $12.25 \pm 1.29^{\mathrm{ab}}$ & $14.63 \pm 2.00^{\mathrm{ab}}$ & $43.00 \pm 25.00^{\mathrm{a}}$ \\
\hline 100 & $8.63 \pm 1.30^{\mathrm{a}}$ & $10.75 \pm 1.60^{\mathrm{a}}$ & $37.50 \pm 21.65^{\mathrm{a}}$ \\
\hline 150 & $9.78 \pm 1.30^{\mathrm{a}}$ & $10.75 \pm 1.31^{\mathrm{ab}}$ & $43.75 \pm 25.77^{a}$ \\
\hline 200 & $12.88 \pm 0.85^{\mathrm{ab}}$ & $14.63 \pm 2.02^{\mathrm{ab}}$ & $50.00 \pm 17.68^{\mathrm{ab}}$ \\
\hline
\end{tabular}

\subsection{Effects of gamma irradiation on yield and yield components of FARO 44 and FARO 60}

\subsubsection{0 grain weight $(g)$}

A significant variation $(\mathrm{P} \leq 0.05)$ in the 100 grains weight $(\mathrm{g})$ was observed in both varieties. The result showed that the 100 grain weight increases as the irradiation dose increases in the exposed plants. This is contrary to the work of Mushtaq and Rakesh [9] who reported a decrease in 100 grain weight as dose increases in wheat (Triticum aestivum L.). Animasaun et al. [13], however, reported average weight of 100 grains for 80 Gy as the highest on their work on Digitaria exills.

\subsubsection{Number of tillers and panicles at maturity}

The result as presented in table 2 revealed the effect of gamma irradiation on number of tillers and panicles of submerged rice. The result showed that, plants exposed to gamma irradiation significantly $(\mathrm{P} \leq 0.05)$ produced highest number of tillers and number of panicles than the control except for FARO 60 where the values were lower than the control. This is in agreement with the work of Raj and Rao [14] who reported that morphological and yield parameters increases as dose increases in exposed rice plants. Similar results were also reported by Falusi et al. [15] in Nigerian sesame cultivars.

\subsubsection{Number of Days to maturity}

The effects of gamma irradiation on the number of days to maturity of submerged FARO 44 and FARO 60 revealed that gamma rays delay flowering and maturity in some of the irradiated plants than the control plants in both varieties. This is in conformity with the work of Arvind et al. [16] who reported that the number of days required for flowering increases with increasing doses of gamma irradiation. 
Table 2 Effects of gamma irradiation on yield and yield components of FARO 44 and FARO 60

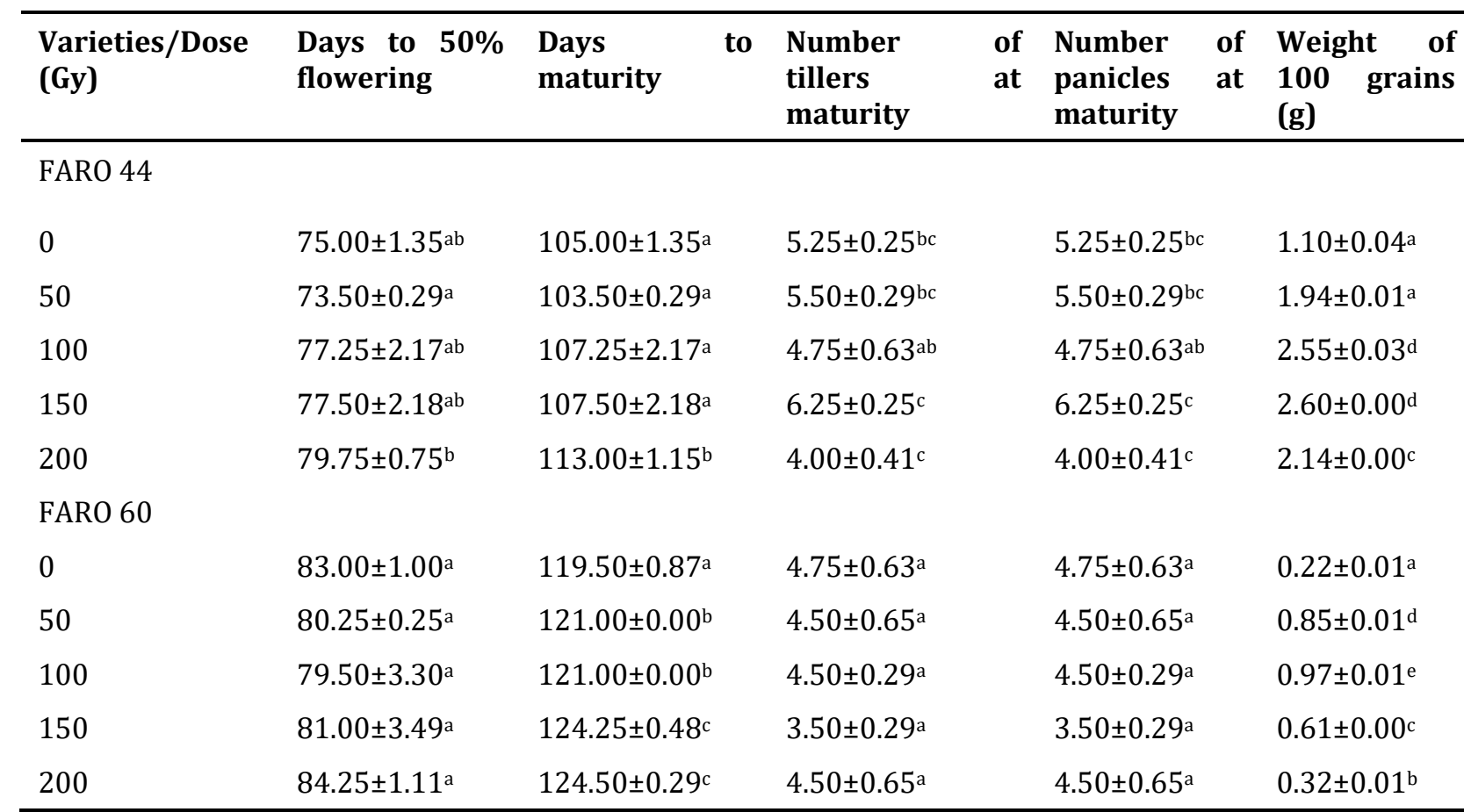

Values are Mean \pm SE. Means with the same superscript down the column are not significantly different $(\mathrm{P}>0.05)$, separated by Duncan multiple range test.

\subsection{Correlation between irradiation doses and agro-morphological parameters of submerged FARO 44 and FARO 60}

The result in table 3 showed the correlation between irradiation doses and agro-morphological parameters of submerged FARO 44 and FARO 60. In FARO 44, the result revealed that gamma irradiation doses exhibited significant positive $(\mathrm{P} \leq 0.05)$ correlation in survival, 100 grain weight, days to $50 \%$ flowering and days to maturity, but negatively correlated with number of panicles at maturity (-0.329) and height after submergence (-0.681). In FAR0 60, only days to maturity exhibited significantly positive $(\mathrm{P} \leq 0.05)$ correlation with doses, height after submergence, survival percentage, 100 grain weight, number of panicles and days to $50 \%$ flowering are negatively correlated. This result showed that lower doses of gamma irradiation have stimulatory effects on the plant height and number of panicles at maturity, whereas, higher doses had inhibitory effects. This is in line with the result of Mishra and Singh [14] who reported that increase in dose of gamma rays increases the seedling height of Isabgol (Plantago ovate, Forsk). The effect of mutagen was also found inhibitory to the plant height as reported by many researchers [18] in Solanum lycopersicum L. The reduction in plant height and other yield components as a result of increased dose of gamma irradiation could be due to physiological processes. Similar assertion was made by [19] in Solanum lycopersicum and [20] in Coriandrum sativum L.

Table 3 Correlation between irradiation dose and agro-morphological parameters of submerged FARO 44 and FARO 60

\begin{tabular}{|c|c|c|c|c|c|c|c|}
\hline Varieties & $\begin{array}{l}\text { Germination } \\
\%\end{array}$ & $\begin{array}{l}\text { HADS } \\
(\mathrm{cm})\end{array}$ & $\begin{array}{l}\text { Survival } \\
\%\end{array}$ & NOP & $\begin{array}{l}50 \% \\
\text { Flowering }\end{array}$ & Maturity & $\begin{array}{l}100 \\
\text { (g) }\end{array}$ \\
\hline FARO 44 & $-0.998 *$ & -0.681 & $0.855^{*}$ & -0.019 & $0.884^{*}$ & $0.875^{*}$ & 0.714 \\
\hline FARO 60 & $-0.990^{*}$ & -0.537 & -0.591 & -0.487 & 0.260 & $0.948^{*}$ & \\
\hline
\end{tabular}

HADS - Height after Submergence, 100 SW (g) - 100 Grains Weight (g), Survival \% - Survival Percentage, NOP - Number of Panicles, $50 \%$ Flowering - Days to 50 Percentage Flowering, Maturity - Days to Maturity 


\section{Conclusion}

In conclusion, it was observed that gamma radiation doses of $150 \mathrm{~Gy}$ and $200 \mathrm{~Gy}$ have positive effect on survival of the plant after been submerged and also on the 100 seed weight of FARO 44 compare to FARO 60 which showed negative effect on most of the parameters. Based on the result of this study, the following recommendations were made:

- Further research should be carried out on submergence tolerance of the promising mutants.

\section{Compliance with ethical standards}

\section{Acknowledgments}

All praises are due to Almighty God for His infinite mercy in sparing our lives and enabling us to reach the conclusion of this research work. We express our gratitude to all the staff of Department of Plant Biology in Federal University of Technology, Mina, Nigeria.

\section{Disclosure of conflict of interest}

The authors of this article declared that there is no conflict of interest.

\section{References}

[1] Akinwale MG, Akinyele BO, Odiyi AC, Nwilene FN, Gregorio G and Oyetunji EO. (2012). Phenotypic Screening of Nigerian Rainfed Lowland Mega rice Varieties for submergence tolerance. Proceeding of the World Congress on Engineering, London UK, 4-6.

[2] Rahman AN and Jianhua Z. (2016). Flood and drought in rice: opposite but may coexist. Food and Energy Security, 5(2), 76-88

[3] Abdelbagi MI, Uma SS, Manzoor HD and David JM. (2013). The contribution of submergence-tolerant (Sub1) rice varieties to food security in flood-prone rainfed lowland areas in Asia. Field Crops Research, 152, 83-93

[4] Barta M and Abdelbagi M. (2013). Tolerance of anaerobic conditions caused by flooding during germination and early growth in rice (Oryza sativa L.). Front Plant Science, 4, 269.

[5] Babei A, Nematzadeh GA, Avagyna V and Hashemi H. (2010). Radio sensitivity studies of mopho-physiological characteristic in some Iranian rice varieties (Oryza sativa L.) in $\mathrm{M}_{1}$ generation. African Journal of Agricultural Research, 5(16), 2124-2130.

[6] Shehata SM, Ammar MH, Abdelkalick AF and Zayed BA. (2009). Morphological, molecular \& biochemical evaluation of Egyptian Jasmine rice variety \& its M5 derived mutants. African Journal of Biotechnology, 8(22), 6110-6116.

[7] Mackill DJ, Ismail AM, Singh US, Labios RV and Paris TR. (2012). Development and rapid adoption of submergence-tolerant (Sub1) rice varieties. Advances in Agronomy, 115, 299-352.

[8] Ahsan AK, Arshad NA, Anizan I, Mehdi FA and Azhar MZ. (2016). Gamma radio sensitivity study on MRQ74 and MR269, two elite varieties of rice (Oryza Sativa L.). Life Science Journals 13(2), 85-91.

[9] Mushtaq AK and Rakesh CV. (2015). Assessment of the effect of gamma irradiation on various morphological and agronomic traits of common wheat (Triticum aestivum L) var.WH-147. European Journal of Experimental Biology, 5(7), 6-11.

[10] Talebi AB, Talebi AB and Shahrokhifar B. (2012). Ethyl Methane Sulphonate (EMS) Induced Mutagenesis in Malaysian Rice (cv. MR219) for Lethal Dose Determination. American Journal of Plant Sciences, 3, 1661 - 1665.

[11] Ambli K and Mullainathan L. (2015). Induced Physical and Chemical studies in M1 generation of Pearl Millet (Pennisetum typhoides) (Burn.) Stapf. Var. Co (Cu)-9. International Journal of Recent Scientific Research, 5(10), 1806-1809.

[12] Ramadoss BR, Ganesamurthy K and Angappan K. (2014). Evaluation of Effect of Gamma rays on Sesame Genotype TTVS 51 and TTVS 19 in M1 Generation. International Journal of Development Research, 4(2), 273- 277. 
[13] Animasaun DA, Morakinyo JA and Mustapha OT. (2014) assessment of the effects of gamma irradiation on the growth and yield of Digitaria exills (Haller). Journal of Applied Biosciences, 75, 6164-6172.

[14] Raj KJ and Rao GJN. (2009). Somaclonal variation in submergence tolerance rice cultivars and induced diversity evaluation. Genetics, 12, 845-901.

[15] Falusi OA, Liman MM, Lateef AA, Adamu GA, Daudu YO and Abejide DR. (2013). Effect of Fast Neutron Irradiation on yield parameters of two Nigerian Sesame cultivars. Academic Journal of Biotechnology, 1(7), 105-108.

[16] Arvind KV, Sitaram S, Rajesh KK, Ram DM and Sharda C. (2017). Gamma radiation effects seed germination, plant growth and yield attributing characters of fennel (forniculum vulgare MILL). International Journal Currmicrobiology and Applied Science, 6(5), 2448-2458.

[17] Mishra M, and Khan AH. (2014) Mutagenic effectiveness and efficiency of individual and combination treatments of EMS and gamma rays in Isabgol (Plantago ovata Forsk). International Journal of Life Sciences, (In Press).

[18] Sikder S, Biswas P, Hazra P, Akhtar S, Chattopadhyay A, Badigannavar AM and D'Souza SF (2013).Induction of mutation in tomato (Solanum lycopersicum L.) by gamma irradiation and EMS. Indian Journal of Genetics, $73(4)$ : 392-399.

[19] Watanabe S, Mizoguchi T, Koh Aoki K, Kubo Y, Mori H, Imanish S, Yamazak Y, Shibata D and Ezura H. (2007) Ethyl methane sulfonate (EMS) mutagenesis of Solanum lycopersicum cv. Micro-Tom for large-scale mutant screens. Plant Biotechnology, 24: 33-38.

[20] Salve KM and More AD. (2014) Effect of Gamma radiation on Seed Germination, Seedling Height and Seedling Injury in Coriandrum sativum Linn. International Journal of Life Sciences, (In Press).

\section{How to cite this article}

Mohammed J, Falusi O, Daudu OAY, Abubakar A, Muhammad LM, Salihu BZ and Titus SD. (2018). Effects of gamma irradiation on submergence tolerance of two selected varieties of lowland rice (Oryza sativa L.). GSC Biological and Pharmaceutical Sciences, 2(3), 31-37. 